\title{
IJKIMMENA
}

1,1

\section{DATA MINING'S CAPABILITIES FOR KNOWLEDGE CREATION IN THE GCC COUNTIES}

\section{Rasha S.Abdul Wahab'}

Ahlia University, Kingdom of Bahrain

\begin{abstract}
Purpose: This paper highlights the importance of using data mining in sustaining development in GCC countries by showing the abilities of data mining techniques of enhancing and improving the discovered knowledge.

Design/methodology/approach: This paper studies the role of data mining techniques to support the creation of scientific capacity to reduce digital divide and accelerate the process of sustaining development. This will help making predictions about future trends using both historical and current data and allowing decision makers and policy makers to make effective knowledge based policies.

Findings: The paper is concluded with the impact of data mining techniques on future development in GCC countries which have been proved based on the current potential for knowledge creation driven by data mining in the different arenas.
\end{abstract}

Keywords: Knowledge; Data Mining; GCC Countries; Development; Information

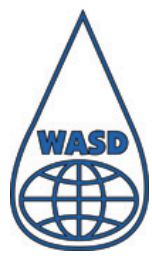

International Journal of Innovation and Knowledge Management in Middle East \& North Africa Vol. 1 No. 1, 2011 E-mail: rash_sh_abdul_wahab@ahliauniversity.edu.bh 


\section{INTRODUCTION}

In developing countries where knowledge is inadequate to accelerate growth and sustain development, data mining could serve an effective tool in knowledge creation and information dissemination. Knowledge for development is required in all stages for supporting rapid economic growth and inducing industrial development. Modern production is a complex process, which requires a substantial investment in human capital, research and development, invention and innovation, and technical progress. In Gulf Cooperation Council (GCC) countries, the ingredients for building infrastructure capacity are still lacking despite their financial endowments and high per capita income. Accelerating economic growth and sustaining development will depend on the capabilities of these countries to create indigenous knowledge and discover new methods to preserve the natural environment and minimise the risk of human activities.

This paper aims to highlight the importance of data mining technique in knowledge creation and its contribution to knowledge transfer in GCC countries. Access to global knowledge is within the reach of all countries. However, acquiring knowledge involves building technological capacity to facilitate access to global knowledge and increase linkages. In this regard, data mining techniques provide a useful tool in the creation of indigenous knowledge which helps countries to alleviate poverty and sustain development. Technological advancement and scientific progress have possibly given the financial potential the GCC countries enjoy and the recent reform initiatives taken for supporting change.

\section{KNOWLEDGE CREATION}

Knowledge plays a central role in the overall development of every society. In the new economy, driven by information
Data mining's capabilities for knowledge creation in the GCC counties 
IJKIMMENA 1,1

and communication technologies (ICTs), it is the knowledge gap that matters for accelerating economic transformation and sustaining development, that is, production of knowledge becomes vital for inducing change and increasing linkages. Closing the knowledge gap requires developing countries to acquire, absorb and communicate knowledge (World Bank, 1998). Recent advances in ICT have facilitated access to knowledge by providing new opportunities for growth and development. Even though the digital divide is still a matter of serious concern to many countries, access to knowledge has become much easier to obtain. The potential for rapid growth is likely to increase due to Internet connection, which in turn facilitates access to global knowledge. As described by United Nations (2006, p. 31), 'Digital opportunities for the South include not just efficiency and entrepreneurial gains but also a potential reconfiguration of how development interventions take place. Demands are emerging for the need to move beyond a pilot syndrome to embrace up-scaling, citizen-centred and broad-based use of ICT'.

Creating knowledge through the Internet reduces cost and enhances productivity, especially in environmental management. Not only the Internet helps gathering information but also facilitates learning, monitoring and evaluating various programs and projects related to the environment. Sharing information is another arena where GCC countries could promote in order to create new knowledge suitable for their own social, economic and natural environment. Mowlana (2001, p. 144) points out that 'Currently, the drive toward market economies combined with the process of deregulation in many Arab countries has opened the way for new international flows of information and products into the Arab world'. However, 'The main issue in the Arab countries is not the transfer of information from the developed countries, but the generation of appropriate information in the Arab world itself. 
An important step toward closing the digital gap is to create local knowledge and discover appropriate technologies. In developing countries, the future prospects for boosting economic performance depend on understanding the environment and on building capacity to gather information and disseminate knowledge. Environmental management represents an integral part of sustainable development. In this respect, the GCC countries are in an advantage position because of their financial capabilities and economic potential.

Knowledge absorption and knowledge creation are vital for promoting modernisation in non-industrialised countries. New techniques and innovation accelerate economic transformation by offering countries new opportunities for enhancing productivity and improving global competitiveness. Knowledge creation is driven by providing incentive and greater investment in research and development as well as by building technological capacity to ensure access to knowledge. 'Because in virtually in all sectors, developing countries are still very far from the technological frontier, they still need to put priority on developing effective means of tapping, the pre-existing and rapidly growing the stock of global knowledge. Developing countries need to put more weight than they do now on understanding, acquiring, adapting, diffusing, and using existing knowledge, including indigenous knowledge' (Dahlman, 2005, p. 20). In order to advance the cause of knowledge and build a knowledge-based society, the Arab world must have a well-defined vision that requires the following:

1. a climate of free and creative expression

2. a high-quality education at all levels

3. a deep commitment to science and scientific research

\section{Data mining's capabilities for knowledge creation in the GCC counties}




\section{IJKIMMENA 4. productive knowledge-based industry}

\section{1,1}

5. a culture of learning and innovation ${ }^{1}$

The Arab countries, including the GCC region, have substantial human and financial potential to advance the knowledge society. At this state, these countries have a 'knowledge deficit' in all aspects of human endeavour. Closing the gap may not be easy without collective commitment on behalf of all countries. A knowledge society is defined as society in which 'knowledge diffusion, production and application become the organising principle in all aspects of human activity: culture, society, the economy, the politics and private life'. ${ }^{2}$ Thus, building a knowledge society will increase human abilities to make use of both local and global knowledge for economic advancement and sustaining development. As a factor of production, knowledge enhances productivity and increases innovation. Given the small population size and environmental constraints in GCC countries, investment in human capital and knowledge creation will ease future challenges by making local industries more productive and more competitive.

\section{DATA MINING}

In modern societies, storage of data and dissemination of information represent a valuable means for decision-making and policy construction. Obtaining good information and collecting reliable data will empower individuals, corporations and government to make better decisions leading to

\footnotetext{
${ }^{1}$ The Brookings Project on U.S. Relations with the Islamic World. (2008). 'A New Millennium of Knowledge? The Arab Human Development Report on Building a Knowledge Society', p. 13.

${ }^{2}$ Arab Human Development Report. (2003). p. 17.
} 
high expectations about future development. In this regard, data mining serves as a storage bank for information that can be sued for knowledge discovery as well as for qualitative and quantitative productivity improvement and economic competitiveness. The complex nature of modern economies underscores the importance of absorption and creation of knowledge to ensure continuity and change. In GCC countries where the state of technology and industrialisation is still lagging behind, data mining facilitates development through knowledge creation and scientific experiments, that is, data mining can be used for forecasting and monitoring future plans which are necessary for sustaining development. The process of data mining and techniques used in knowledge discovery includes several operational steps. They involve data selection and transformation, analysing the data via data mining algorithm and presenting the results for decision makings and future forecasting. Both businesses and governments are to benefit from such techniques especially in formulating market strategies and macroeconomic policies.

Environmental management requires collecting and storing data about climatic changes, rainfalls, pollution, energy production and consumption, and water resources. Data mining is a technique that helps in analysing data to produce information that can be converted into knowledge. The usefulness of this technique stems from its contribution to produce indigenous knowledge and discover new methods suitable for the local environment. Similarly, the usefulness of data mining is to help making predictions about future trends using both historical and current data. Such information assists environmentalists devising measures to monitor and make contingency plans for minimising the impact of climatic and geographical forces on the environment. Data mining technology can be used to generate new information and discover new knowledge for strengthening environmental management.
Data mining's capabilities for knowledge creation in the GCC counties 
IJKIMMENA Under such circumstances, data mining technique enables 1,1 formulating knowledge through data warehousing, data selection and evaluation. Mathematically, data mining develops algorithms and constructs models for use to extract information and establish new patterns. There is a great prospect that data mining will become a powerful tool in decision makings due to rapid advancement in computer technology and software packages. These technologies have increased the usage of enormous sets of data and allowing decision makers and policy makers to make effective knowledge-based policies.

In GCC countries, adaptation of such methods enables these countries to sustain growth by producing information and creating new methods to meet the challenges facing their societies. Mining and production of oil and gas represent the main economic activities in most countries in the Middle East. The use of land and pollution of the air and water are among the important consequences of production, transportation, storage and consumption of energy. Sustainable development requires building an effective management system to enable collecting large amount of data for analysing and monitoring environmental trends. The GCC countries must develop a system to store and retrieve information that assists in reducing environmental risk and strengthens the capability of these countries to manage the environment. Knowledge discovery for environmental management requires the establishment of institutions capable of collecting data and conducting research. As a tool of analysis and instrument of search for new information, data mining enhances the potential of knowledge discovery. Efforts should be made by both public and private enterprises to share knowledge through networking and exchange information about the environment.

Managing environmental risks has become more urgent, particularly in developing countries, where environmental 
degradation, civil wars, water shortages, deforestation human negligence and inadequate institutional infrastructure are among the important challenges facing sustainable future development. The current technology used in GCC countries is mostly imported technology not necessarily suitable for development. Environmentally friendly technology should provide high degree of safety to avoid pollution and waste disposal. Knowledge discovery induces the creation of new techniques that reduce environmental imbalances. Fostering growth underscores the creation of indigenous technologies to ensure environmental protection and reduce pollution.

\section{KNOWLEDGE MANAGEMENT AND KNOWLEDGE CREATION}

Knowledge has become essential for promoting organisational development and inducing market competitiveness. A nation's knowledge assets are its most valuable resources reflecting the capabilities to induce rapid socioeconomic change and advance technological development. As a factor of production, knowledge represents a new opportunities, especially for developing countries, for deepening integration and for sustaining development. The knowledge based-capacity comprises the institutional bodies, research centres, infrastructure and technology that can facilitate the absorption, application, sharing and discovery of knowledge. Building knowledge capacity depends on 'information that is extracted from data'. Learning about managing knowledge and dissemination of information is a prerequisite for knowledge absorption and knowledge creation. As Drucker (1993, p. 39) points out, 'management is a generic function of all organisations, whatever their specific mission. It is the generic organ of the knowledge society'. Knowledge is defined to emerge from 'the application, analysis, and productive use of data and or/information. In other word, knowledge can be seen as data or
Data mining's capabilities for knowledge creation in the GCC counties 
IJKIMMENA information with a further layer of intellectual analysis add1,1

ed, where it is interpreted, meaning is attached, and is structured and linked with existing systems of beliefs and bodies of knowledge. Knowledge therefore provides the means to analyse and understand data/information, provides beliefs about the causality of events/actions and provides the basis to guide meaningful/ action thought' (Hislop, 2005, pp. 15 16). Knowledge management can help businesses, students, decision makers and individuals to share information and exchange knowledge to increase organisational efficiency and enhance market competitiveness. Knowledge management enlarges the capacity to utilise external knowledge for creating indigenousness knowledge suitable for local markets. In this regard, data mining techniques can be used to identify relevant information and analyse data for obtaining appropriate forecast about future trends. In countries such as the GCC, such approach is important for innovation and creating new knowledge. Knowledge management makes use of limited resources to narrow the gap between poor and rich countries by accelerating the process of knowledge absorption and speeding up the development of new techniques. Such trends could help to empower workers and institutions to reduce the digital gap and to increase the productivity of the economy.

\section{SUSTAINABLE DEVELOPMENT}

The failure of development theories in promoting growth in most developing countries during the last few decades has increased the discourse about sustainable development as an alternative to conventional development models. The concept of sustainable development is better understood in relation to environmental management. Economic activities are directly linked to the ecology and, therefore, achieving a balance between production and consumption of natural resources, and the environment becomes necessary for environmental 
protection. In this regard, discovery of new knowledge and availability of information reduce environmental imbalances and facilitate sustainable development.

In the GCC countries, there is a need for building adequate technological, institutional and scientific capacities to create indigenous knowledge for sustaining development. Universities and vocational schools can play an important role by utilising the existing knowledge including data mining and e-learning to induce innovation and increase the potential of knowledge creation. The concept of sustainable development is driven by environmental forces, and therefore, learning about the environment becomes vital for creating a support system needed for building indigenous knowledge capacity. Global knowledge and information are accessible through modern technologies and Internet connectivity.

Empowering people with knowledge about development requires making use ICT for creating knowledge and developing new techniques. ICT increases global linkages which in turn, facilitate technology transfer and induce invention and innovation. In the case of the GCC countries, such technologies allow greater market flexibility and enhance knowledge absorption. Sustainable development underscores the importance of traditional knowledge and value systems in promoting rapid socioeconomic transformation. Experience with modern technologies, mainly of Western origin, has proven to be inadequate by causing environmental imbalances and increasing the social cost. In addition to environmental degradation, these technologies are increasing dependency of GCC countries on global markets. ICT along with the use of e-learning and data mining techniques could facilitate the discovery of new knowledge and invent new methods to support indigenous development. In GCC countries, externalities are responsible for some of the environmental degradations.

\section{Data mining's capabilities for knowledge creation in the GCC counties}


IJKIMMENA This requires greater initiatives for sharing information and 1,1 collecting data to reduce the risk of cross border pollution. Interdependencies of the economies of the GCC countries increase environmental linkages through trade, transportation, energy consumption and production. Conducting scientific research and building awareness provide new opportunities for rapid economic transformation.

People in developing countries are lacking to adequate capacity for sustaining development. For instance, heavy dependency of GCC countries on production and consumption of fossil fuels could increase the risk of environmental degradation. In addition, the replacement of these non-renewable resources must be selective to minimise the risk of pollution. Thus, knowledge of the environment becomes prerequisite for empowering people skills and increasing technological innovation, that is, building technological capacity provides a foundation for knowledge discovery that deals with existing environmental conditions. In GCC countries, governments need to invest in acquiring knowledge through data mining and other techniques by making use of both traditional and international knowledge. Utilisation of data mining for environmental management depends on the existence of technology and adequacy of infrastructure.

Oil and gas resources in GCC countries exercise a substantial influence over future socioeconomic trends. The extraction and consumption of these resources are in direct link to the environment, and therefore, building capacity for establishing harmonious relations with the environment becomes necessary for sustaining development. This requires learning about environmental management by creating indigenous knowledge capable of sustaining social and economic growth without damaging the environment. 'Indigenous practice was based on a sense of harmony with the natural environment, 
which resulted in sustainable practice and sustainable use. The traditional use of natural resources was based on traditional values' (World Bank, 2004, p. 30).

\section{CONCLUSION}

In this paper, the use of data mining techniques as an instrument for knowledge discovery is highlighted. Modernisation and rapid industrialisation depend on building technological capacity to enhance developing countries capabilities applying, absorbing and creating knowledge. Currently, the digital divide between developed and developing countries can be reduced with the use of ICT technologies as well as data mining techniques to gather information and discover new knowledge.

Environmental management has become a key in sustainable development. Learning and gaining knowledge and information about the environment is vital for accelerating growth and alleviating poverty. In GCC countries, the potential for higher growth is possible because of their financial endowments and investment in human capital development. Using modern scientific methods and technological advancement, including e-learning, data mining and electronic computers, facilitate information dissemination and knowledge creation. Both public and private sectors must contribute to the creation of indigenous knowledge through investment in research and development, skills improvement and learning. Building such capacity strengthens scientific applications and induces incentive for knowledge discovery. Data mining techniques could be used to support the creation of scientific capacity to reduce digital divide and accelerate the process of sustaining development.

In GCC countries, long-term indigenous growth driven by local cultural, economic and environmental forces is necessary

\author{
Data mining's \\ capabilities \\ for knowledge \\ creation in the \\ GCC counties
}


IJKIMMENA for sustainable development. Currently, the region derives most 1,1

of its income from a non-renewable resource, which is expected to be depleted in the future. Thus, without replacement, economic development will be constrained unless alternative resource is found. The current potential for knowledge creation driven by data mining and e-learning could have a substantial impact on future development in GCC countries.

\section{BIOGRAPHY}

Dr. Rasha Shaker received her Ph.D. in Data Mining and Evolutionary Algorithm, from the Iraq University of Technology in 2005. She is currently Assistant Professor in Computer Science, College of Information Technology, Ahlia University. She has published several papers reflecting her diverse research interests spanning: Evolutionary Algorithm, Data mining, and to E-Leaning, knowledge management. In addition, to her teaching assignments, Dr. Abdul-wahab is supervising dissertation at both Ph.D and master levels. She is interested in research activities, mainly in the area of knowledge discover and Evolutionary Techniques.

\section{REFERENCES}

Dahlman, C.J. (Ed.). (2005). 'Finland as a Knowledge Economy', World Bank, Washington.

Drucker, P. (1993). 'Post-Capitalist Society', Butterworth, London.

Hislop, D. (2005). 'Knowledge Management in

Organizations', Oxford University Press, New York.

Mowlana, H. (2001). 'Information in the Arab world', Cooperation South, No. 1, p. 144. 
United Nations. (2006). 'Gender in the Information Society', Elsevier, New Delhi.

Data mining's capabilities for knowledge

World Bank. (1998). 'World Development Report 1998/99, creation in the Knowledge for Development', Oxford University Press, GCC counties New York.

World Bank. (2004). 'Indigenous Knowledge: Local Pathways to Global Development', World Bank, Washington. 